\title{
Spécificité de la réponse d'immunité cellulaire chez un insecte
}

\author{
par Y. CARTON \\ Laboratoire de Génétique évolutive, C.N.R.S., F 91190 Gif-sur-Yvette
}

Dans les études sur les phénomènes immunitaires chez les Invertébrés, les résultats les plus significatifs ont été obtenus par la technique des greffes tégumentaires ; plusieurs groupes zoologiques ont été étudiés: les Oligochètes (Chateauraynaud-Duprat, 1970), les Echinodermes (Hildeman et al., 1974) et les Tuniciers (Hildeman et Reddy, 1973). On conçoit que chez les insectes un tel protocole expérimental soit très difficile à mettre en œuvre à cause de la forte chitinisation de leurs téguments (Scott, 1971) ; cependant, ils présentent le net avantage de pouvoir s'élever au laboratoire. Aussi, contrairement aux trois autres groupes, il est tout à fait possible de faire varier les parentés génétiques entre donneur et receveur.

En m’inspirant du même principe, j'ai été amené à pratiquer des implantations d'œufs dans la cavité générale d'un insecte (Pimpla instigator, Hyménoptère) au dernier stade larvaire. J'ai implanté des œufs (greffon) de diverses origines, donc de parentés génétiques variées avec la larve (receveur). La réaction cellulaire développée par le receveur consiste en la formation d'une capsule hémocytaire autour de l'œuf (Salt, 1970) ; son épaisseur, étant uniforme sur tout le pourtour de l'implant, s'est révélée être un très bon indicateur de l'intensité de la réponse immunitaire.

\section{Matériel et méthodes.}

Pour les transplants xénogéniques, on a utilisé des œufs de Drosophila melanogaster (Diptère) et des œufs haploïdes d'Apechtis compuctor (Hyménoptère). Pour les transplants allogénique et isogénique, on a utilisé des œufs haploïdes de Pimpla instigator, ces œufs provenant de femelles vierges prélevées respectivement dans l'élevage de masse ou dans l'élevage d'une souche consanguine.

Le receveur est représenté par une larve mâle de cinquième stade larvaire de Pimpla en diapause; l'œuf est déposé dans sa cavité générale par la face ventrale au niveau du troisième segment abdominal. 
Un jour, deux jours, 4 jours et 8 jours après la greffe, on dissèque cette larve ; l'épaisseur de la capsule hémocytaire formée autour de l'œuf est mesurée.

\section{Résultats.}

Les résultats sont présentés sur la figure 1 . On note que la réaction atteint son maximum d'intensité au quatrième jour dans les différents types de transplants. Les réactions d'immunité cellulaire observées sont d'autant plus fortes que l'éloignement

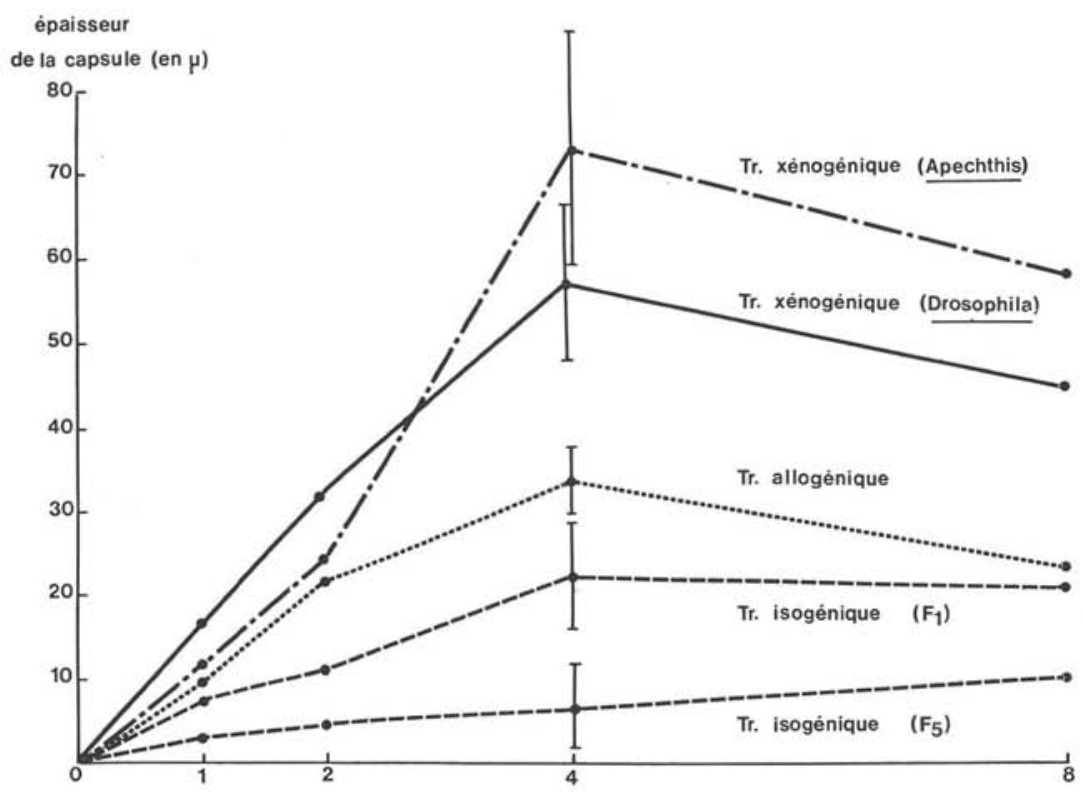

Fic. 1. - Variation de l'intensité de la réaction hémocytaire en fonction du temps et en fonction du degré de parenté entre receveur et implant.

génétique entre donneur et receveur est plus important. Il est intéressant de noter les résultats obtenus lors des transplants isogéniques: dans ce cas, l'implant et le receveur sont issus de la même femelle qui, elle-même, provient d'une souche consanguine. On note alors que la réaction immunitaire est d'autant plus faible que le taux de consanguinité est plus grand (une ou cinq générations de croisements consanguins). On s'est assuré que la larve réceptrice issue de cette lignée consanguine avait conservé intact son potentiel de réponse : l'implantation d'un œuf de Drosophila chez cette larve déclenche une réaction au quatrième jour (épaisseur de la capsule : 49,6 $\mu \pm 4,5$ ) très comparable à celle obtenue dans la transplantation xénogénique (épaisseur : $57,8 \mu \pm 9,7)$. 


\section{Conclusions.}

Ainsi, il a été possible par cet artifice expérimental de greffes d'œufs de «mesurer» le niveau de discrimination immunitaire atteint chez un insecte. La larve de Pimpla instigator est apte à distinguer le soi des différents non-soi [première étape dans la phylogénie de la réponse immunitaire d'après Hildemann (1974)]. De plus, elle s'avère apte à faire la distinction entre les différents non-soi (deuxième étape). L'intensité de sa réponse hémocytaire est modulée suivant le degré de parenté génétique qu'elle présente avec l'implant; plus ce dernier est éloigné génétiquement et plus la réaction immunitaire est intense.

\section{Bibliographie}

Carton (Y.), 1976. - Isogenic, allogenic and xenogenic transplants in an Insect species. Transplantation, 21, 17-22.

Chateauraynaud-Duprat (P.), 1970. - Specificity of allograft reaction in Eisenia foetida. Transplant. Proc., 11, 222-225.

Hildeman (W. H.), 1974. - Some new concepts in immunological phylogeny. Nature, 250, 116-120.

Hildeman (W. H.) et Reddy (A. L.), 1973. - Phylogeny of immune responsiveness : marine Invertebrates. Fed. Proc., 32, 2188-2194.

Hildeman (W. H.), Dix (T. G.) et Collins (J. D.), 1974. - Tissue transplantation in diverse marine Invertebrates, in: Contemp. top. Immunobiol., 4, 141-150.

SALt (G.), 1970. - The cellular defence reactions of Insects. Cambridge University Press, édit., $116 \mathrm{p}$.

ScotT (M. T.), 1970. - Recognition of foreignness, in Invertebrates Transplant., 11, 78-86. 